\title{
Advantages of using Plasma FIB Over a Gallium LMIS Source
}

\author{
B.W. Arey ${ }^{1}$, D.E. Perera ${ }^{1}$, L. Kovarik ${ }^{1}$, J. Liu ${ }^{1}$, O. Qafoku ${ }^{2}$, A. R. Felmy ${ }^{2}$, R. Kelley ${ }^{3}$, T. \\ Landin $^{3}$, R. Alvis ${ }^{3}$ \\ Pacific Northwest National Laboratory, Environmental Molecular Science Laboratory, \\ 3335 Innovation Boulevard, Richland, WA 99354, USA \\ 2 Pacific Northwest National Laboratory, 902 Battelle Boulevard, Richland, WA 99354, \\ USA \\ 3 FEI Co., 5350 NE Dawson Creek Drive, Hillsboro, Or 97124, USA
}

For over 20 years, gallium liquid metal ion source (LMIS) technology has been the workhorse charged particle beam for the focused ion beam (FIB) industry. In recent years the gas field ion source (GFIS) and plasma field ion source (PFIB) are gaining in popularity as an alternative to LMIS. One of the driving forces is the gallium implantation into the material and the artifacts one must deal with.

In our experiments we are exploring the interaction with the gallium source and xenon plasma source has on the $\mathrm{CO}_{2}$ reaction on olivine minerals.

Fayalite, the iron-rich end member of the olivine series (Mg,Fe) ${ }_{2} \mathrm{SiO}_{4}$, occurs in abundance in the Earth's upper mantle and it can be a significant constituent of basaltic rocks. The isolated tetrahedral structure of fayalite can breakdown during reaction with aqueous solutions and it is known that the dissolution of fayalite is accelerated if high temperatures, acidic solutions and far from equilibrium conditions are present. During fayalite dissolution its constituents ( $\mathrm{Fe}^{2+}$ and silica) will be released from the structure and can participate in precipitation reactions with nearby anions to form secondary minerals: (hematite, goethite, sulfites, carbonates, amorphous silica). In this study we will present the new methods for determining the spatial distribution of the light elements $(\mathrm{Na}, \mathrm{Li}$,and $\mathrm{Ca}$ ) within the mineral fayalite. These elements may play a role in carbonation reactions of fayalite under super critical $\mathrm{CO}_{2}$ conditions.

High Resolution Scanning Transmission Electron Microscopy (STEM), a highly-focused electron probe is raster-scanned across the material, and various types of scattering are collected as a function of position. The transmitted electrons at high scattering angle can be collected to form high-resolution, chemically sensitive, atomic number (Z-) contrast images. The $\mathrm{x}$-rays generated can be collected using an energy-dispersive X-ray spectroscopy (EDS) detector and used to form high spatial resolution compositional maps. Electron energy losses can be detected using a Gatan image filter (GIF) to map the compositional and electronic properties of materials.

Atom Probe Spectroscopy (APT), is a state-of-the-art analytical method that allows for three-dimensional elemental mapping with near atomic resolution. It is a powerful tool that can provide unique compositional information on a variety of materials systems such as complex alloys, semiconductor materials and devices, and ceramic material. 
This work was supported by the U. S. Department of Energy (DOE), Office of Basic Energy Sciences through a Single Investigator Small Group Research (SISGR) grant at Pacific Northwest National Laboratory (PNNL). This research was performed using EMSL, a national scientific user facility sponsored by the Department of Energy's Office of Biological and Environmental Research located at Pacific Northwest National Laboratory.

PNNL is operated for DOE by Battelle Memorial Institute under Contract\# DE-AC0576RL0-1830.

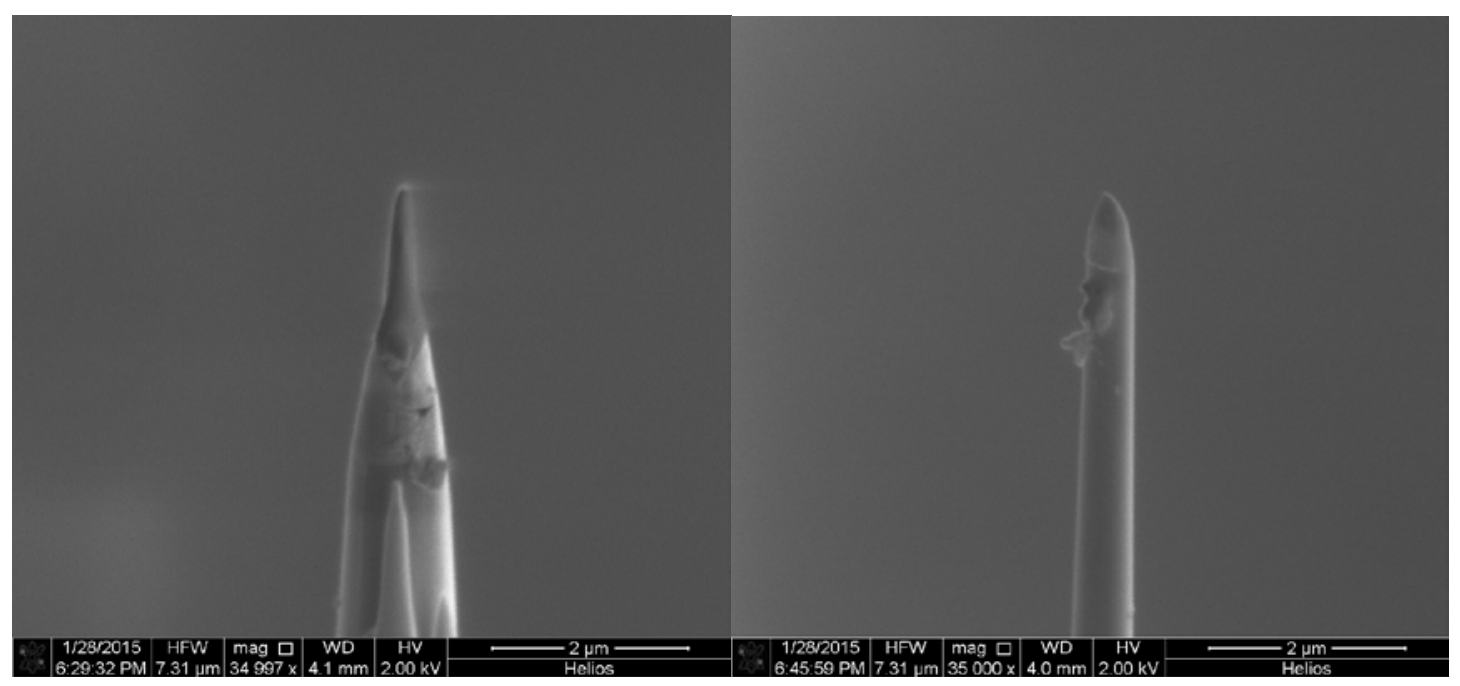

Figure 1: Ga APT after reaction with $\mathrm{CO}_{2}$ : Figure 2: Xe APT after reaction with $\mathrm{CO}_{2}$ 